\title{
Are there Relationships between the VDR-FokI Polymorphism and Vitamin D and the Insulin Resistance in Non-melanoma Skin Cancer (NMSC) Patients? A Protocol for Case-control Studies
}

\author{
Fatemeh Rezaeian $^{1}$, Bahareh Nikooyeh ${ }^{2}$, Tirang R. Neyestani ${ }^{2 *}$ \\ 1- PhD candidate in Nutrition Sciences, Faculty of Nutrition Sciences and Food Technology, Shahid Beheshti University of Medical Sciences, Tehran, \\ Iran \\ 2- Faculty of Nutrition and Food Technology, National Nutrition and Food Technology Research Institute, Shahid Beheshti University of Medical
} Sciences, Tehran, Iran

\section{A B S T R A C T}

Background and Objectives: Evidence indicate relationships between the sunlight exposure, vitamin D status and non-melanoma skin cancer (NMSC) risk. Vitamin D receptor (VDR) polymorphisms have been linked to metabolic changes in insulin resistance and various cancers. The purpose of this study is to investigate relationships between the sunlight exposure and the NMSC risk. Furthermore, relationships between the VDR FokI polymorphism and vitamin D status and the insulin resistance in NMSC patients will be assessed.

Materials and Methods: A hospital-based case-control study is designed. Participants are randomly categorized into case and control groups. Eligible patients are adults who meet the inclusion criteria with verified diagnosis of NMSC with signed informed consents. Totally, 73 NMSC diagnosed cases and 72 healthy controls are recruited and their sunlight exposure data and genetic information are collected via interviews and high-resolution melting (HRM), respectively.

Conclusions: There are controversial reports on the relevance of sunlight exposure to non-melanoma skin cancer risk due to the dual effect of UVB radiation on promoting vitamin $\mathrm{D}_{3}$ synthesis in the skin and increasing DNA damage leading to skin cancer. Results of this study provide data on how much sunlight exposure includes beneficial health effects with no skin cancer risks. Vitamin D status may affect risks of insulin resistance-linked diseases such as cancers. Findings will contribute to the current knowledge of the roles of vitamin D, insulin resistance and FokI polymorphism in skin cancer development.

Keywords: Vitamin D, Insulin resistance, Non-melanoma skin cancer, FokI polymorphism

\section{Introduction}

Non-melanoma skin cancer (NMSC) is the most common increasing type of malignancies in Caucasians worldwide (1). Several clinical and epidemiological studies have demonstrated links between the high ultraviolet (UV) exposure and the skin cancer risk (2). The UV exposure may result in DNA damage in skin cells and is considered as the leading environmental risk factor for all types of skin cancers (3). There are substantial controversies in scientific communities regarding optimum sunlight exposures to set balances between the positive and negative effects of solar UV-exposure (4). It is estimated that nearly half of the populations worldwide are affected by impaired vitamin D status. Strong evidence indicate possible protective roles of vitamin $D$ against cancers, bone fractures, cardiovascular diseases (CVD), autoimmune diseases, type-2 diabetes, influenza and depression (5). Epidemiologic studies support possible protective roles of vitamin D in cancers, including colorectal (6, $7)$ breast $(8,9)$, prostate $(10,11)$, ovarian (12) and kidney cancers (13). However, the association of vitamin D with risk of skin cancer has to be clarified (14). Previous experimental studies have reported possible roles of vitamin $\mathrm{D}$ against ultraviolet radiation-induced DNA damage and skin cancer 
development $(15,16)$. The biologically active form of vitamin $\mathrm{D}, \quad 1,25(\mathrm{OH}) 2 \mathrm{D}$, or calcitriol, has photoprotective effects and may decrease UV-induced cell death, immunosuppression and mutagenic activity (17).

Vitamin $\mathrm{D}$ action is generally mediated by binding to VDR (18). The VDR gene is involved in various pathways including calcium absorption, differentiation and proliferation of immune cells and cellular processes associated with carcinogenesis, such as proliferation, differentiation and apoptosis (19). Up to date, several polymorphisms of VDR have been identified; of which, FokI polymorphism (rs2228570) leads to altered protein structures (20) and subsequent less transcriptional activities (21). Impaired functions of VDR have been associated with increased risks of epidermal carcinogenesis through increasing cellular proliferation and decreasing differentiation of keratinocytes (22). Previous studies have reported conflicting results on whether various VDR polymorphisms can predispose increased risks of NMSC (23-26). The possible negative link between circulating $25(\mathrm{OH}) \mathrm{D}$ concentrations and glucose homeostasis including insulin resistance has been suggested in some studies $(27,28)$. In a prospective study, baseline serum $25(\mathrm{OH}) \mathrm{D}$ was inversely associated with 10-year risk of hyperglycemia, metabolic syndrome and insulin resistance (29). It is noteworthy that VDR gene is expressed in adipocytes and pancreatic beta cells; by which, it could affect body composition via directly regulating differentiation and metabolism of adipocytes or indirectly by modulation of insulin (30). However, evidence for the effects of this polymorphism on $25(\mathrm{OH}) \mathrm{D}$ concentration, adiposity and insulin resistance in patients with NMSC is rare (31).

\section{Aims and research questions}

The current study will address the following questions:

(1)Do NMSC patients have longer duration of occupational direct sun exposure than that unaffected people do?

(2) If yes, does it have any effects on the patient vitamin D status? In other words, do NMSC patients have a higher vitamin D status, compared to that unaffected people do?
(3) Are there any associations between IR and NMSC?

(4) Are there any associations between VDR FokI polymorphism, vitamin D status and NMSC risk?

\section{Hypothesis}

The hypothesis describes that people with VDR FokI polymorphism are at increased risk of vitamin D deficiency, insulin resistance and NMSC.

\section{Materials and Methods}

\section{Study population}

At least 70 patients with skin tumor, including squamous cell carcinoma (SCC) and basal cell carcinoma (BCC), are recruited from dermatology clinics of Razi Hospital, Tehran University of Medical Sciences, Tehran, Iran. Controls consist of 70 age and sex-matched healthy volunteers.

\section{Information and data collection}

Subjects are contacted by phone and informed of the study objectives and, if they agree to participate, asked to sign written informed consents. Data on age, sex, education level, marital status, medication and supplement use history, disease history, body mass index (BMI), body fat percentage, blood pressure, sun exposure habits including approximate time of sunlight exposure per day, day period of exposure (morning, noon or afternoon) and sunscreen use. Figure 1 shows the study protocol in brief.

\section{Inclusion/exclusion criteria}

Patients are eligible if they are diagnosed with nonmelanoma skin cancer within the past three months and are 65 years of age or younger. Participants are excluded from the study if they are taking nutritional supplements such as vitamin D, calcium, omega-3 and antioxidant or medications that modify vitamin $\mathrm{D}$ metabolism (corticosteroids, estrogens and calcitonins) for at least three months prior to study and if they have history of other cancers, renal diseases or liver diseases.

\section{Control identification}

For every recruited individual, an unrelated healthy age and sex-matched volunteer is recruited from the publicity. The aforementioned exclusion criteria is also used for the control group. 


\section{Sample size calculation}

Based on the following formula of:

$n=\frac{\left(z_{\alpha / 2}+z_{\beta}\right)^{2} \sigma^{2}(1+1 / k)}{\varepsilon^{2}}$

$n=\frac{(1.96+0.84)^{2}(1+1 / 1)}{0.25}$

\section{Cases}

(Identified from the hospital database)
With a power of $80 \%$, a two-sided $5 \%$ significant level, expected $25(\mathrm{OH}) \mathrm{D}$ concentration in control group $\left(\varepsilon=\mu_{1}-\mu_{2}\right)$ and effect size of 0.5 , a minimum of 59 participants per arm is needed. Therefore, 70 people are recruited to compensate potential losses during the study.

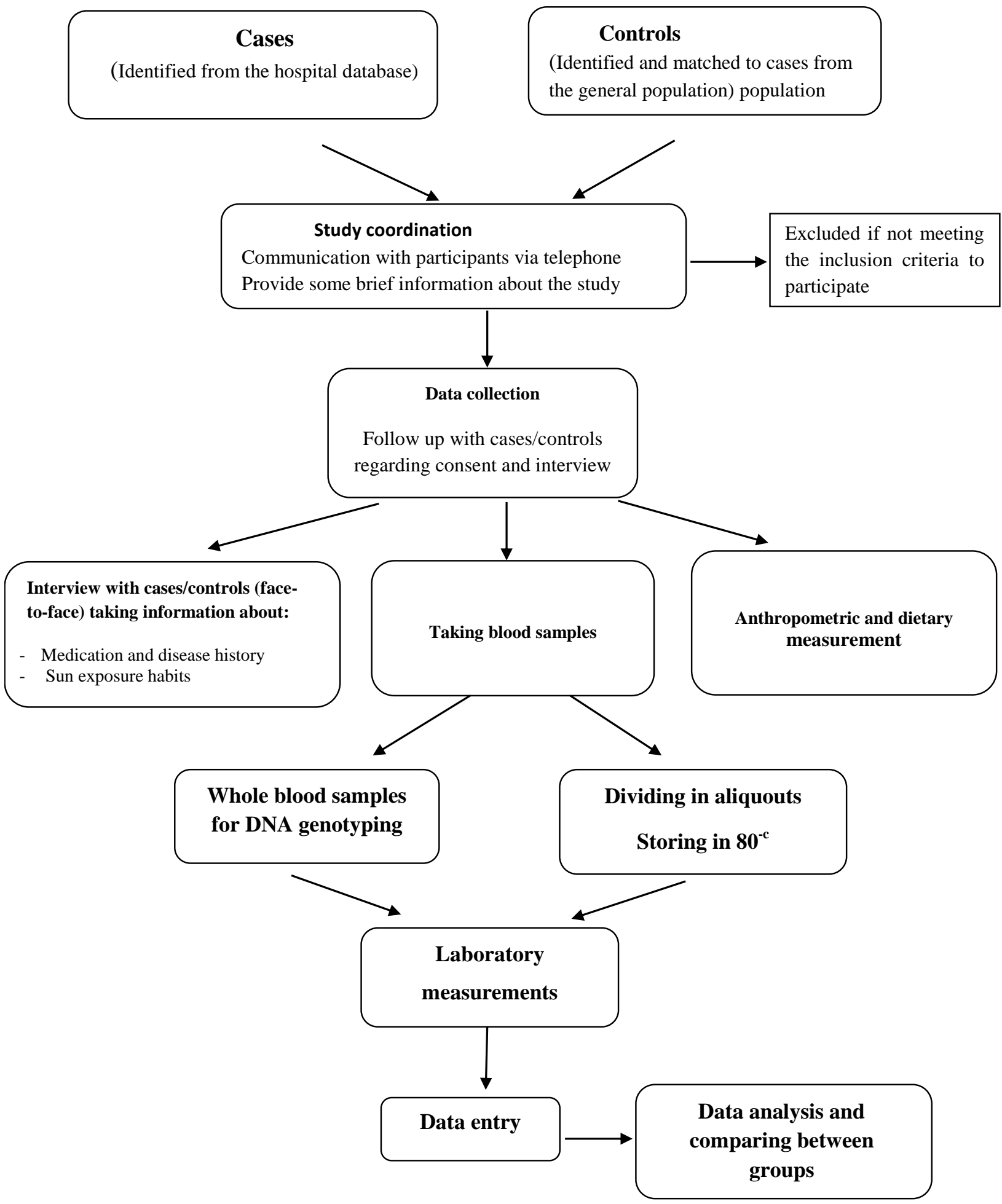

Figure 1. Strategies for the identification and recruitment of cases and controls, data collection and laboratory investigations 


\section{Anthropometric measures and blood pressure}

Height is measured to the nearest of $0.1 \mathrm{~cm}$ using stadiometer (Seca 216, Seca, Hamburg, Germany). Weight is measured with light clothing and no shoes using digital scale (Seca 808; Seca, Hamburg, Germany) to the nearest of $0.1 \mathrm{~kg}$. The BMI is calculated using the equation body weight $(\mathrm{kg})$ / height $^{2}(\mathrm{~m})$. Moreover, BMI is majorly categorized as follows: underweight $(<18.5)$, normal (18.5-24.9) and overweight $(>25.0)$ according to 2004 World Health Organization (WHO) recommendations. Hip circumference (HC) and waist circumference (WC) are measured using measuring tape to the nearest 0.1 $\mathrm{cm}$. The WC is measured at the approximate midpoint between the lowest rib and iliac crest after a normal expiration. The $\mathrm{HC}$ is measured at the level of the greater trochanters. Sitting blood pressure is assessed using digital sphygmomanometer (BC08; Beurer GmbH, Ulm, Germany). All assessments and assessments are carried out by trained nutritionists.

\section{Blood samples}

After $12-14 \mathrm{~h}$ of fasting, $10 \mathrm{~mL}$ of venous blood are collected by expert phlebotomists. After centrifugation, serum is separated and then aliquoted and stored at $-80{ }^{\circ} \mathrm{C}$ until use. Serum markers include $25(\mathrm{OH})$ vitamin $\mathrm{D}$, intact parathyroid hormone (iPTH), insulin, fasting serum glucose (FSG) and lipid profiles of triglyceride (TG), low-density lipoprotein-cholesterol (LDL-C), high-density lipoprotein-cholesterol (HDL-C) and total cholesterol (TC). Fasting whole blood samples are collected from all participants for DNA genotyping. The extracted DNA integrity and purity are checked using NanoDrop Spectrophotometer (Thermo-Fisher Scientific, USA) by measuring ratio of the absorbance at 260 and $280 \mathrm{~nm}$. Then, DNA extracts are stored at $20 \mathrm{C}^{\circ}$ until further genotyping analyses.

\section{Glycemic status and lipid profile}

Briefly, FSG and components of lipid profile are analyzed using enzymatic colorimetric methods (Pars Azmoon, Tehran, Iran). Serum insulin is assessed using enzyme immunoassay (EIA) kit (Demeditec Diagnostics GmbH, Kiel, Germany). Homeostasis model assessment of insulin resistance (HOMA-IR) is used as an index of insulin resistance and is calculated using the following formula (32):

HOMA-IR $=$ [fasting insulin $(\mathrm{mU} / \mathrm{mL}) \times$ fasting glucose $(\mathrm{mg} / \mathrm{dL})] / 405$

\section{Serum calcidiol and iPTH assessments}

Serum 25(OH)D and iPTH are assessed using EIA kits (Euroimmun, Medizinische Labordiagnostika AG, Germany). Participants are categorized as normal when their total $25(\mathrm{OH}) \mathrm{D}$ concentrations are equal to or exceed $30 \mathrm{ng} / \mathrm{mL}$, whereas insufficient and deficient participants have 25(OH)D levels of 20-29 or less than $20 \mathrm{ng} / \mathrm{mL}$, respectively (33-36).

\section{DNA Extraction and Genotyping}

PrimePrep Genomic DNA Isolation Kit (GeNet Bio, Daejeon, South Korea) is used for the extraction of genomic DNA, according to the manufacturer's instruction. For VDR FokI polymorphism (rs2228570), the forward primer is 5'GTCAAAGTCTCCAGGGTCAG-3' and the reverse primer is 5'-GCCTGCTTGCTGTTCTTAC-3'. Highresolution melting (HRM) assay using StepOnePlus Thermal Cycler (Applied Biosystems, Foster City, USA) is used for genotyping. The PCR reactions are prepared in a final volume of $20 \mu \mathrm{L}$ using $5 \times$ Hot FIREPol HRM Mix (HRM PCR buffer, HotStarTaq Plus DNA polymerase, nucleotides and EvaGreen dye), $0.3 \mathrm{nM}$ (final concentration) of each forward and reverse primer and $30 \mathrm{ng}$ of DNA. The PCR conditions are as follows: initial denaturationactivation step at $95{ }^{\circ} \mathrm{C}$ for $15 \mathrm{~min}$, followed by 40 cycles (denaturation at $95{ }^{\circ} \mathrm{C}$ for $15 \mathrm{~s}$, annealing at 61 ${ }^{\circ} \mathrm{C}$ for $20 \mathrm{~s}, 72{ }^{\circ} \mathrm{C}$ for $20 \mathrm{~s}$ ) and a HRM step from 60 to $95{ }^{\circ} \mathrm{C}$ rising at $0.1{ }^{\circ} \mathrm{C} / \mathrm{s}$. Curves for each duplicate are checked on the shape and peak height to meet reproducibility. Normalized and temperature-shifted melting curves from HRM (suggestive of SNP) are distinguished. Direct Sanger sequencing is used to verify genotyping results.

\section{Statistical analysis}

Mean \pm SD (standard deviation) and frequencies are used to express continuous variables and categorical variables, respectively. Kolmogorov-Smirnov test is used to test normality. Comparisons between the groups are carried out using Mann-Whitney, independent samples t-test and chi-squared test when appropriate. Furthermore, ANOVA or Kruskal-Wallis test is used for the comparison of means of variables in various polymorphism groups, for data with normal or abnormal distribution, respectively. For multiple comparisons, Tukey's HD correction is used. Association of the VDR genotype with the risk of skin cancer is estimated by computing the odds ratios 
(OR) and $95 \%$ confidence intervals $(95 \% \mathrm{CI})$ using logistic regression analysis. Hardy-Weinberg equilibrium (HWE) is tested using goodness-of-fit chi-squared test to compare the genotype frequencies with the expected frequencies in controls. The statistical analyses are carried out using IBM SPSS Statistics v.23.A (IBM Analytics, USA). Two-tailed values of less than 0.05 are considered statistically significant.

\section{Discussion}

In this study, a protocol is described for the casecontrol studies to show if there are relationships between the VDR-FokI polymorphism and vitamin D and the insulin resistance in non-melanoma skin cancer (NMSC) patients. The study demonstrates the potential functions of VDR in assessment of body composition, glucose homeostasis and mechanism of insulin release. Therefore, genetic variations in VDR genes may contribute to pathogenesis of the metabolic syndrome (37). There are limited data on associations between the Mets and the NMSC risk. Mechanisms, through which it may alter skin carcinogenesis, have not been described yet $(38,39)$. To the best of the authors' knowledge, this will be the first report on possible associations between the Fok-I VDR gene polymorphism and the IR in NMSC populations. Thus, providing information on the effects of MetS components and vitamin D status in improvement of skin conditions such as NMSC will contribute to development of guidelines for the individuals who are at risk of NMSC.

\section{Ethics and dissemination}

Written informed consent will be obtained from the eligible patients prior to participation in the study. Ethical approval will be received from the Ethics Committee of the National Nutrition and Food Technology Research Institute (NNFTRI), Shahid Beheshti University of Medical Sciences (SBUM), Tehran, Iran.

\section{Competing interests}

The authors declare no competing interests.

$\begin{array}{ll}\text { Abbreviations } \\ \text { 25(OH)D } & \text { 25-hydroxyvitamin D } \\ \text { IU } & \text { International Unit } \\ \text { NMSC } & \text { Non-melanoma skin cancer } \\ \text { BCC } & \text { Basal cell carcinoma } \\ \text { SCC } & \text { Squamous cell carcinoma }\end{array}$

HOMA-IR Homeostasis model assessment of insulin resistance

$\begin{array}{ll}\text { UV } & \text { Ultraviolet } \\ \text { UVB } & \text { Ultraviolet B } \\ \text { VDR } & \text { Vitamin D receptor } \\ \text { VDD } & \text { Vitamin D deficiency } \\ \text { BMI } & \text { Body Mass Index } \\ \text { WHO } & \text { World Health Organization } \\ \text { HC } & \text { Hip circumference } \\ \text { WC } & \text { Waist circumference } \\ \text { SBP } & \text { Systolic blood pressure } \\ \text { DBP } & \text { Diastolic blood pressure } \\ \text { ELISA } & \text { Enzyme-linked immunosorbent assay } \\ \text { HRM } & \text { High-resolution melting } \\ \text { HWE } & \text { Hardy-Weinberg equilibrium } \\ \text { MetS } & \text { Metabolic syndrome }\end{array}$

\section{Financial disclosure}

The authors declared no financial interest.

\section{References}

1. Apalla Z, Lallas A, Sotiriou E, Lazaridou E, Ioannides D. Epidemiological trends in skin cancer. Dermatol Pract Concept. 2017;7(2):1-6.

2. Ananthaswamy HN. Sunlight and Skin Cancer. J Biomed Biotechnol. 2001;1(2):49-

3. Savoye I, Olsen CM, Whiteman DC, Bijon A, Wald L, Dartois L, et al. Patterns of Ultraviolet Radiation Exposure and Skin Cancer Risk: the E3N-SunExp Study. J Epidemiol. 2018;28(1):27-33.

4. Mason RS, Reichrath J. Sunlight vitamin D and skin cancer. Anti-cancer agents in medicinal chemistry. 2013;13(1):83-97.

5. Nair R, Maseeh A. Vitamin D: The "sunshine" vitamin. Journal of pharmacology \& pharmacotherapeutics. 2012;3(2):118-26.

6. Kang W, Lee S, Jeon E, Yun Y-R, Kim K-H, Jang J-H. Emerging role of vitamin D in colorectal cancer. World J Gastrointest Oncol. 2011;3(8):123-7.

7. McCullough ML, Zoltick ES, Weinstein SJ, Fedirko V, Wang M, Cook NR, et al. Circulating Vitamin D and Colorectal Cancer Risk: An International Pooling Project of 17 Cohorts. J Natl Cancer Inst. 2019;111(2):158-69.

8. Obaidi J, Musallam E, Al-Ghzawi HM, Azzeghaiby SN, Alzoghaibi IN. Vitamin D and its relationship with breast cancer: an evidence based practice paper. Glob J Health Sci. 2014;7(1):261-6.

9. Estébanez N, Gómez-Acebo I, Palazuelos C, Llorca J, Dierssen-Sotos T. Vitamin D exposure and Risk of Breast Cancer: a meta-analysis. Sci Rep. 2018;8(1):9039-. 
10. Song Z-Y, Yao Q, Zhuo Z, Ma Z, Chen G. Circulating vitamin $\mathrm{D}$ level and mortality in prostate cancer patients: a dose-response meta-analysis. Endocr Connect. 2018;7(12):R294-R303.

11. Swami S, Krishnan AV, Feldman D. Vitamin D metabolism and action in the prostate: implications for health and disease. Mol Cell Endocrinol. 2011;347(12):61-9.

12. Guo H, Guo J, Xie W, Yuan L, Sheng X. The role of vitamin $\mathrm{D}$ in ovarian cancer: epidemiology, molecular mechanism and prevention. $\mathrm{J}$ Ovarian Res. 2018;11(1):71-.

13. Manucha W, Juncos LI. The protective role of vitamin $\mathrm{D}$ on the heart and the kidney. Ther Adv Cardiovasc Dis. 2017;11(1):12-9.

14. Tang JY, Fu T, Lau C, Oh DH, Bikle DD, Asgari MM. Vitamin D in cutaneous carcinogenesis: part II. Journal of the American Academy of Dermatology. 2012;67(5):817.e1-28.

15. Bikle DD. Protective actions of vitamin D in UVB induced skin cancer. Photochem Photobiol Sci. 2012;11(12):1808-16.

16. Dixon KM, Tongkao-On W, Sequeira VB, Carter SE, Song EJ, Rybchyn MS, et al. Vitamin D and death by sunshine. Int J Mol Sci. 2013;14(1):1964-77.

17. Nair-Shalliker V, Fenech M, Forder PM, Clements MS, Armstrong BK. Sunlight and vitamin D affect DNA damage, cell division and cell death in human lymphocytes: a cross-sectional study in South Australia. Mutagenesis. 2012;27(5):609-14.

18. Swapna N, Vamsi UM, Usha G, Padma T. Risk conferred by FokI polymorphism of vitamin D receptor (VDR) gene for essential hypertension. Indian J Hum Genet. 2011;17(3):201-6.

19. Ochs-Balcom HM, Cicek MS, Thompson CL, Tucker TC, Elston RC, J Plummer S, et al. Association of vitamin $\mathrm{D}$ receptor gene variants, adiposity and colon cancer. Carcinogenesis. 2008;29(9):1788-93.

20. Burns EM, Elmets CA, Yusuf N. Vitamin D and skin cancer. Photochemistry and photobiology. 2015;91(1):201-9.

21. Orlow I, Roy P, Reiner AS, Yoo S, Patel H, Paine S, et al. Vitamin D receptor polymorphisms in patients with cutaneous melanoma. International journal of cancer. 2012;130(2):405-18.

22. Caini S, Boniol M, Tosti G, Magi S, Medri M, Stanganelli I, et al. Vitamin D and melanoma and nonmelanoma skin cancer risk and prognosis: a comprehensive review and meta-analysis. Eur J Cancer. 2014;50(15):2649-58

23. Denzer N, Vogt T, Reichrath J. Vitamin D receptor (VDR) polymorphisms and skin cancer: A systematic review. Dermato-endocrinology. 2011;3(3):205-10.
24. Han J, Colditz GA, Hunter DJ. Polymorphisms in the MTHFR and VDR genes and skin cancer risk. Carcinogenesis. 2007;28(2):390-7.

25. Lesiak A, Norval M, Wodz-Naskiewicz K, Pawliczak R, Rogowski-Tylman M, Sysa-Jedrzejowska A, et al. An enhanced risk of basal cell carcinoma is associated with particular polymorphisms in the VDR and MTHFR genes. Experimental dermatology. 2011;20(10):800-4.

26. Qadir J, Majid S, Rashid F, Hassan I, Sajad P, Bhat YJ, et al. Vitamin D receptor gene polymorphism and risk of skin cancer patients of Kashmiri population (India): A case-control study. Our Dermatology Online/Nasza Dermatologia Online. 2018;9(3).

27. Cade C, Norman AW. Vitamin D3 improves impaired glucose tolerance and insulin secretion in the vitamin D-deficient rat in vivo. Endocrinology. 1986;119(1):8490.

28. Yu F, Cui LL, Li X, Wang CJ, Ba Y, Wang L, et al. The genetic polymorphisms in vitamin $\mathrm{D}$ receptor and the risk of type 2 diabetes mellitus: an updated metaanalysis. Asia Pacific journal of clinical nutrition. 2016;25(3):614-24.

29. Forouhi NG, Luan J, Cooper A, Boucher BJ, Wareham NJ. Baseline serum 25-hydroxy vitamin $D$ is predictive of future glycemic status and insulin resistance: the Medical Research Council Ely Prospective Study 19902000. Diabetes. 2008;57(10):2619-25.

30. Rahmadhani R, Zaharan NL, Mohamed Z, Moy FM, Jalaludin MY. The associations between VDR BsmI polymorphisms and risk of vitamin D deficiency, obesity and insulin resistance in adolescents residing in a tropical country. PloS one. 2017;12(6):e0178695-e.

31. Xia Z, Hu Y, Han Z, Gao Y, Bai J, He Y, et al. Association of vitamin $D$ receptor gene polymorphisms with diabetic dyslipidemia in the elderly male population in North China. Clinical interventions in aging. 2017;12:1673-9.

32. Matthews DR, Hosker JP, Rudenski AS, Naylor BA, Treacher DF, Turner RC. Homeostasis model assessment: insulin resistance and beta-cell function from fasting plasma glucose and insulin concentrations in man. Diabetologia. 1985;28(7):412-9.

33. Holick MF. Vitamin D Deficiency. New England Journal of Medicine. 2007;357(3):266-81.

34. Chapuy MC, Preziosi P, Maamer M, Arnaud S, Galan $\mathrm{P}$, Hercberg $\mathrm{S}$, et al. Prevalence of vitamin D insufficiency in an adult normal population. Osteoporosis international : a journal established as result of cooperation between the European Foundation for Osteoporosis and the National Osteoporosis Foundation of the USA. 1997;7(5):439-43.

35. Holick MF, Siris ES, Binkley N, Beard MK, Khan A, Katzer JT, et al. Prevalence of Vitamin D inadequacy among postmenopausal North American women 
receiving osteoporosis therapy. The Journal of clinical endocrinology and metabolism. 2005;90(6):3215-24.

36. Bischoff-Ferrari HA, Giovannucci E, Willett WC, Dietrich T, Dawson-Hughes B. Estimation of optimal serum concentrations of 25-hydroxyvitamin $\mathrm{D}$ for multiple health outcomes. The American journal of clinical nutrition. 2006;84(1):18-28.

37. Scragg R, Sowers M, Bell C. Serum 25-hydroxyvitamin $\mathrm{D}$, diabetes, and ethnicity in the Third National Health and Nutrition Examination Survey. Diabetes care. 2004;27(12):2813-8.
38. Nagel G, Bjorge T, Stocks T, Manjer J, Hallmans G, Edlinger M, et al. Metabolic risk factors and skin cancer in the Metabolic Syndrome and Cancer Project (MeCan). The British journal of dermatology. 2012;167(1):59-67.

39. Padhi T. Metabolic syndrome and skin: psoriasis and beyond. Indian journal of dermatology. 2013;58(4):299305. 